\title{
Isı Şoku Protein Ailesinden Hsp70 Genlerinin Okaliptüs Genomunda Saptanması ve Karakterizasyonu
}

\author{
Yasemin CELLIK ALTUNOĞLU \\ Kastamonu Üniversitesi, Mühendislik ve Mimarlık Fakültesi, Genetik ve Biyomühendislik Bölümü \\ Sorumlu yazar: ycaltunoglu@kastamonu.edu.tr
}

Geliș Tarih: 26.07.2016

\begin{abstract}
Özet
Isı şoku proteinleri (Heat shock proteins: Hsp), birçok canlıda hücre büyümesi ve canlılığının devamı için kritik öneme sahiptir. Hsp70 proteinleri, Hsp'lerin bir sınıfıdır ve yeni sentezlenmiş veya yanlış katlanmış proteinlerin katlanmasında, bir araya gelerek çökmesinin engellenmesinde, membran boyunca taşınmasında ve düzenleyici proteinlerin aktivitesinin kontrolünde rol alırlar. Okaliptüs (Eucalyptus grandis), evrimsel ve ekolojik durumu ve marjinal bölgelere uyum yetenekleri sebebiyle çok yıllık bitkilerin biyolojisi ve evrimi hakkında önemli bilgilere ulaşılmasını sağlayabilecek önemli bir bitkidir. Tüm genom dizisi çıkarılan okaliptüste Hsp proteinleri henüz belirlenmemiştir. Bu amaçla, bu önemli bitkide biyoinformatik araçlar kullanılarak 21 adet Hsp70 geni ( EgHsp70) tanımlanmıştır. En fazla EgHsp70 geni (7 adet) 10. okaliptüs kromozomu üzerinde bulunurken 1, 2, 4 ve 11. kromozomlarda bu genlere rastlanmamıştır. Evrimsel ilişkilerini tespit etmek amacıyla belirlenen proteinler için filogenetik ağaç oluşturulmuştur. Bu ağaca göre EgHsp70 proteinleri 5 ayrı sınıfa ayrılmış ve aynı sınıfta yer alan proteinlerin gen yapısının benzer ekzon-intron organizasyonuna sahip olduğu görülmüştür. Okaliptüs Hsp70 proteinlerinin tahmini moleküler fonksiyon şekli, bağlanma aktivitesi olurken, biyolojik işlevlerinin ise organizmaya özgü ve metabolik işlevlerdeki rolleri olduğu belirlenmiştir. Hücrede en çok yerleşim gösterdikleri yerler organel, hücre içi veya hücre bölümü kısımları olurken, tahmini sekonder yapılarında sıklıkla $\alpha$-heliks zincirlerinin bulunduğu ve bu proteinlerin tamamının asidik karakterde ( $\mathrm{pI}<7$ ) olduğu gözlenmiştir. Çalışma, EgHsp70 genlerinin fonksiyonlarının çalışılması için sonraki çalışmalara 1şık tutucu niteliktedir ve farklı türlerde $H s p 70$ genlerinin evriminin anlaşılmasına önemli katkılar sağlayabilir.
\end{abstract}

Anahtar Kelimeler: Isı şoku proteinleri (Hsp), Eucalyptus grandis, genom analizi, gen ontoloji analizi, filogenetik ağaç

\section{Determination and Characterization of Hsp70 Genes from Heat Shock Protein Family in} Eucalyptus Genome

\begin{abstract}
Heat shock proteins (Hsp) are critically important for cellular development and viability in many organisms. Hsp70 proteins are a group of Hsps and responsible for folding of newly synthesized or misfolded proteins, prevention of their aggregation, carriage of them along the membrane and control of regulatory protein activities. Eucalyptus (Eucalyptus grandis) is an important plant to reach considerable knowledge about biology and evolution of perennial plants due to its evolutionary and ecological position and ability to adapt to marginal regions. Whole genome sequence of eucalyptus was analyzed but Hsps have not been determined yet. Using bioinformatics tools, 21 Hsp70 genes (EgHsp70) were determined in this important plant. The highest number of EgHsp 70 genes were located on the 10th chromosome ( 7 genes) but 1st, 2nd, 4th and 11th chromosomes do not carry $H s p 70$ genes on them. Phylogenetic tree was constructed to determine evolutionary relationships of defined proteins. According to phylogenetic tree, EgHsp70 proteins were divided into 5 clusters and proteins which were in the same clusters had similar exon-intron organization. Predicated molecular function style of eucalyptus Hsp70 proteins was binding activity and their roles in single organism process and metabolic process determined as their biological activities. They were found mostly in the inner part of the cell, organelle or cell parts and their predicated secondary structures were constructed by mostly $\alpha$-helix chains and all these proteins were acidic $(\mathrm{pI}<7)$. This study may be instructive for further researches and may be helpful for understanding of evolution of $H s p 70$ genes in different species.
\end{abstract}

Keywords: Heat shock proteins (Hsp), Eucalyptus grandis, genome wide identification, gene ontology analysis, phylogenetic tree.

\section{Giris}

Isı şoku proteinleri (Heat shock proteins: Hsp), birçok canlıda hücre büyümesi ve canlılığının devamı için kritik öneme sahip protein ailelerinden biridir. Bitkilerde bu protein ailesi, yüksek ve düşük sicaklık, kurakl1k, tuzluluk gibi abiyotik stres koşullarının yanında bitkilerin normal gelişim aşamalarında da görev alır (Krishna ve ark., 1995; Sabehat ve ark., 1998; Lopez-Matas ve ark., 2004; Swindell ve ark., 2007; Cho ve Choi, 2009; Zou ve ark., 2012). Bu 
görevlerini ise yeni veya strese maruz kalmış proteinlerin katlanmasina aracilık ederek ve proteinlerin bir araya gelmesi, transkolasyonu ve degredasyonu gibi işlemlerde rol alarak yaparlar. Moleküler ağırlıkları dikkate alındığında Hsp proteinleri, küçük Hsp proteinleri (sHsp), Hsp70 (DnaK/Ssa), Hsp60 (şaperonin), Hsp90 (HtpG) ve Hsp100 (Clp) olmak üzere beş farklı gruba ayrılmaktadır (Wang ve ark., 2004). Bu büyük protein ailesinin Hsp70 proteinleri grubu ilk defa, 1960'larda yanlışlıkla yüksek sıcaklıkta inkübasyona bırakılan Drosophila'da (meyve sineği) kromozomların analizi sırasında bilinmeyen bir proteinin gen ekspresyonunun artışının görülmesi ile keşfedilmiş̦tir (Ritossa, 1996).

Hücrede 'housekeeping' gen gibi işlev gören Hsp70 protein grubu, yeni sentezlenmiş veya yanlış katlanmış proteinlerin katlanmasinda, proteinlerin bir araya gelerek çökmesinin engellenmesinde, çeşitli proteinlerin membran boyunca taşınmasında ve düzenleyici proteinlerin aktivitesinin kontrolünde rol alırlar (Bukau ve Horwich, 1998; Hartl ve ark., 2011). Hsp70 proteinleri, ATP'ye bağlanarak ADP'ye hidroliz eden bir nükleotid bağlanma bölgesi (NBD) olarak da isimlendirilen N-terminal ATPaz bağlanma bölgesi ve katlanmaya aracılık eden lineer peptid segmentleriyle ilişkili olan substrat bağlanma bölgesi (SBD) içerir (Mayer ve Bukau, 2005; Dragovic ve ark., 2006). Genellikle Hsp70 proteinleri aktivitelerini, şaperon döngüsü olarak adlandırılan ve bu grup proteinlerin yukarıda belirtilen bölgeleri aracılığıyla gerçekleşen substrat bağlanması, ATP bağlanması ve hidrolizini içeren döngünün tekrarlanması şeklinde gösterirler (Lund, 2001).

Pek çok bitkide Hsp70 proteinlerinin biyolojik rollerini belirlemek amaciyla çalışmalar yapılmıştır. Örnek verilecek olursa, AtHsp70-15 isimli proteinin yokluğunda bitkide büyüme geriliğinin görüldüğü, bu bitkilere sicak stresi uyguladığında ise bitkilerde ölüm oranının arttığı belirlenmiştir (Jungkunz ve ark., 2011). Yine bir Hsp70 grup proteinini kodlayan kloroplast cpHsc70-1 geni mutant Arabidopsis bitkisi tohumları sicaklık stresine maruz kaldığında kusurlu fenotiplerin ortaya çıktığ1 görülmüştür (Su ve $\mathrm{Li}$ 2008).
Arabidopsis'de dişi gametofit gelişiminde gerekli bir Hsp70 geni olan BIP geninin (Maruyama ve ark., 2010), tütün bitkisinde (Nicotiana tabacum) ise su stresine karş1 koruma sağladığ 1 belirlenmiştir (Alvim ve ark., 2001). Pirinçte BIP1/OsBIP3 geninin susturulduğu veya yüksek ekspresyonunun sağlandığ 1 çalışmalarda ise bu genin programlı hücre ölümü (Qi ve ark., 2011) ve tohum gelişiminde (Wakasa vd,. 2011) rol aldığ 1 saptanmıştır. Yoncada (Medicago sativa) MsHSP70-1 geninin nodül oluşumunda rol oynadığı gözlenmiştir (He ve ark., 2008). Pamukta lif oluşumu ve gelișimi basamaklarında da pek çok Hsp70 proteininin rol aldığg gösterilmiştir (Zhang ve ark., 2014). Domateste ise olgun anterlerde Hsc70 transkriptlerine rastlanılmıştır (Duck ve Folk 1994). Buradan hareketle Hsp70 grup proteinlerin bitkilerin hem normal gelişimi hem de stres koşulları altında önemli rol oynadığı söylenebilir, bununla birlikte bu proteinlerin okaliptüs de dâhil pek çok organizmada henüz tanımlanmadığı ve fonksiyon analizlerinin yapılmadığı bilinmektedir.

Okaliptüs (Eucalyptus grandis), doğal olarak Avustralya'nın New South Wales eyaletinin kuzeyi ve Queensland eyaletinin güneyindeki kıyıya yakın yerlerde dağılım göstermektedir (Byrne, 2008). Türkiye'de ise Ege, Orta ve Doğu Karadeniz Bölgelerinin kıyı bölümleri ile Akdeniz Bölgesinin kıyı ve alçak kesimlerinde rastlanılmaktadır (Gülbaba, 1990). Dünyada dikili orman ağaçları içerisinde hızlı uyum ve büyüme yeteneği ve gelişkin fiber ve odun nitelikleri ile okaliptüs odunlu orman ağaçları arasında en yaygın cins olarak ilk sirada yer almaktadır (20 milyon ha) (Iglesias ve Wiltermann, 2009). Okaliptüs ağaçları, iyi bir kâğıt, biyomalzeme ve biyoenerji kaynağı olmasının yanında tıbbi ve endüstriyel kullanımı olan yüksek çeşitlilik ve konsantrasyonda esansiyel yağ kaynağıdır. Odunlu bitkilerin büyüme performans1 ve uyum yeteneklerinin moleküler temelinin ortaya çıkarılması, dünyanın birçok bölgesinde sürdürülebilir enerji ve biyomalzeme ekonomisi için önemli bir firsat sunmaktadır. Okaliptüs de evrimsel ve ekolojik durumu ve marjinal bölgelere uyum yetenekleri sebebiyle çok y1llık bitkilerin biyolojisi ve evrimi hakkında 
önemli bilgilere ulaşılmasını sağlayabilecek önemli bir bitkidir (Myburg ve ark., 2014; Bartholomé ve ark., 2015).

Okaliptüs (Eucalyptus grandis) genom dizisi, 2014 yılında yayınlanmıştır (Myburg ve ark., 2014). Tüm genom dizilerinin ortaya çıkarılması, biyoinformatik araçlarla gen ailelerinin belirlenmesine olanak sağlamaktadır. Bilgimize göre Hsp 70 genlerinin belirlendiği sınırlı sayıdaki çalışmalar Arabidopsis (Lin ve ark., 2001; Sung ve ark., 2001), soya (Zhang L. ve ark., 2015), kavak (Zhang J. ve ark., 2015; Yer ve ark., 2016), çeltik (Jung ve ark., 2013; Sarkar ve ark., 2013), pamuk (Zhang ve ark., 2014) bitkilerinde yapılmıştır. Tüm genom verileri kullanılarak yapılan bu çalışmalarda da genellikle, $H s p 70$ genleri belirlenmiş ve bu genlere ait kromozomal yerleşimleri, filogenetik ilişkileri, korunmuş motifleri, tahmini sekonder yapıları, biyolojik fonksiyonları, dokuya özgü ekspresyon profilleri ve abiyotik stres koşullarına karşı bu gen ailesinin yanıtları analiz edilmiştir. Şimdiye kadar okaliptüste ise Hsp gen ailesi üyeleri tanımlanmamıştır. Buradan hareketle çalıșmamızda Hsp ailesi üyeleri içerisinde önemli bir grubu oluşturan $H s p 70$ genlerinin tanımlanması ve kromozomlar üzerindeki yerleşimleri, filogenetik ilişkileri, tahmini biyolojik rolleri, moleküler fonksiyonları, hücresel yerleşimleri ve sekonder yapılarının belirlenmesi amaçlanmıştır.

\section{Materyal ve Yöntem \\ Okaliptüs genomunda $H s p 70$ genlerinin belirlenmesi}

Isı şoku proteinleri ile ilgili bir veri tabanı olan Hspir veri tabanından (http://pdslab.biochem.iisc.ernet.in/hspir)

(Kumar ve ark., 2012) daha önce 15 farkl1 bitkide (Arabidopsis thaliana, Cucumis sativus, Glycine max, Hordeum vulgare, Medicago truncatula, Nicotiana tabacum, Oryza sativa, Physcomitrella patens subsp. patens, Ricinus communis, Solanum lycopersicum, Sorghum bicolor, Triticum aestivum, Vigna radiata, Vitis vinifera, Zea mays) belirlenen Hsp70 protein dizileri çekilmiștir. Bu diziler kullanılarak tüm genom dizisi tamamlanmış bitki genomlarını içeren Phytozome v.11 veri tabanında (Goodstein ve ark., 2012) BLASTP taramas1 yapılarak Eucalyptus grandis'e ait ve bu dizilerle homolog diziler saptanmıştır. Daha sonra CLC Genomic workbench 7.5 v (Qiagen, Almanya) yardımıla Hsp70 proteinlerine ait korunmuş bölge analizleri, içerdikleri geniş protein koleksiyonuyla proteinde işlevsel bölgelerin belirlenmesine imkân veren Pfam (http://pfam.sanger.ac.uk/) ve Smart (http://smart.emblheidelberg.de/) (Letunic ve ark., 2012) veri tabanlarında yapılmıştır. Korunmuş bölge içeriklerine göre ilgili okaliptüs amino asit dizileri çalışmaya alınmış ve Phytozome v.11 veri tabanı (Goodstein ve ark., 2012) aracılığıyla bu proteinlerin genomik ve kodlayıcı bölge dizileri de ileri analizlerde kullanılmak üzere toplanmıştır. Ayrica Expasy ProtParam arac1 (http://web.expasy.org/protparam/)

(Gasteiger ve ark., 2003) ile belirlenen okaliptüs Hsp70 dizilerinin protein uzunluğu ve moleküler ağırlığı, izoelektrik noktası (pI) ve kararsızlık indeksi gibi özellikleri hesaplanarak Tablo 1 oluşturulmuştur.

\section{Hsp70 genlerinin okaliptüs kromozomlarındaki yerleşimleri ve gen yapısının belirlenmesi}

Tanımlanan okaliptüs $H s p 70$ genlerinin (EgHsp70) 11 okaliptüs kromozomu üzerindeki yerleşim yerlerini belirlemek amaciyla Phytozome v.11 veri tabanında okaliptüs dizilerine karşı1lk BLASTP taraması yapılmış ve genlerin fiziksel pozisyonları (bç) belirlenmiştir. Daha sonra Mapchart program1 (Voorrips, 2002) aracılığıyla okaliptüs kromozomları üzerinde yerleşimleri gösterilmiştir. EgHsp 70 genlerinin gen yapısını belirlemek amacıyla 'Gene structure display server' (http://gsds.cbi.pku.edu.cn/) (Hu ve ark., 2015) kullanılarak EgHsp70 genlerine ait genomik diziler ile kodlayıcı bölge dizileri karşılaştırılmış ve genlerin ekzon ve intron yapıları belirlenmiştir. 
Tablo 1. Okaliptüste belirlenen $21 \mathrm{Hsp} 70$ proteininin özellikleri

\begin{tabular}{|c|c|c|c|c|c|c|c|c|c|}
\hline \multirow[t]{2}{*}{ İsim } & \multirow{2}{*}{$\begin{array}{l}\text { Phytozome } \\
\text { isimlendirmesi }\end{array}$} & \multicolumn{4}{|c|}{ Okaliptüs Genomundaki Yerleşimi } & \multirow[t]{2}{*}{ pI } & \multirow{2}{*}{$\begin{array}{l}\text { Moleküler } \\
\text { ağırlığı }\end{array}$} & \multirow{2}{*}{$\begin{array}{l}\text { Karasızlık } \\
\text { endeksi }\end{array}$} & \multirow{2}{*}{$\begin{array}{l}\text { Stabil } \\
\text { veya } \\
\text { değil }\end{array}$} \\
\hline & & Kromozom & $\begin{array}{l}\text { Başlangıç } \\
\text { (bç) }\end{array}$ & Bitiş (bç) & $\begin{array}{c}\text { Protein } \\
\text { uzunluğu } \\
\text { (aa) }\end{array}$ & & & & \\
\hline EgHsp70-01 & Eucgr.C01277.1.p & 3 & 16680129 & 16691011 & 939 & 5,22 & 103158.5 & 44.57 & değil \\
\hline EgHsp70-02 & Eucgr.E01024.1.p & 5 & 9739020 & 9743484 & 719 & 5,32 & 79530.1 & 32.23 & stabil \\
\hline EgHsp70-03 & Eucgr.E03189.1.p & 5 & 52702819 & 52705355 & 522 & 5,8 & 56963.0 & 32.21 & stabil \\
\hline EgHsp70-04 & Eucgr.F00767.1.p & 6 & 10940705 & 10946469 & 718 & 6,17 & 80300.1 & 46.22 & değil \\
\hline EgHsp70-05 & Eucgr.F00767.2.p & 6 & 10940705 & 10946469 & 711 & 6,16 & 78950.9 & 43.34 & değil \\
\hline EgHsp70-06 & Eucgr.F03980.1.p & 6 & 50569822 & 50580464 & 782 & 4,98 & 85929.7 & 38.09 & stabil \\
\hline EgHsp70-07 & Eucgr.G00235.1.p & 7 & 3743313 & 3747727 & 706 & 5,5 & 75805.8 & 35.44 & stabil \\
\hline EgHsp70-08 & Eucgr.G01045.1.p & 7 & 16326049 & 16330473 & 684 & 5,62 & 73079.8 & 35.54 & stabil \\
\hline EgHsp70-09 & Eucgr.H03518.1.p & 8 & 48623823 & 48627257 & 572 & 5,4 & 61943.4 & 35.02 & stabil \\
\hline EgHsp70-10 & Eucgr.H04513.1.p & 8 & 61049487 & 61052735 & 618 & 5,1 & 68266.4 & 31.88 & stabil \\
\hline EgHsp70-11 & Eucgr.I02583.1.p & 9 & 36990732 & 36995044 & 682 & 5,75 & 73296.0 & 38.64 & stabil \\
\hline EgHsp70-12 & Eucgr.I02771.1.p & 9 & 38552803 & 38556824 & 718 & 5,45 & 76032.8 & 33.61 & stabil \\
\hline EgHsp70-13 & Eucgr.J00023.1.p & 10 & 455644 & 458906 & 649 & 5,13 & 71269.7 & 33.69 & stabil \\
\hline EgHsp70-14 & Eucgr.J00023.3.p & 10 & 455644 & 458906 & 615 & 5,03 & 67401.4 & 35.36 & stabil \\
\hline EgHsp70-15 & Eucgr.J00025.1.p & 10 & 506608 & 510151 & 742 & 5,8 & 81246.0 & 36.40 & stabil \\
\hline EgHsp70-16 & Eucgr.J00025.2.p & 10 & 506608 & 510151 & 735 & 5,98 & 80628.4 & 36.34 & stabil \\
\hline EgHsp70-17 & Eucgr.J02987.1.p & 10 & 35509576 & 35515795 & 851 & 5,15 & 93754.9 & 41.69 & değil \\
\hline EgHsp70-18 & Eucgr.J02991.1.p & 10 & 35534460 & 35541365 & 874 & 5,09 & 95664.3 & 44.10 & değil \\
\hline EgHsp70-19 & Eucgr.J03127.1.p & 10 & 36763093 & 36765332 & 652 & 5,43 & 71470.0 & 34.15 & stabil \\
\hline EgHsp70-20 & Eucgr.L01770.1.p & scaffold_349 & 833 & 3551 & 572 & 5,17 & 63495.1 & 31.90 & stabil \\
\hline EgHsp70-21 & Eucgr.L03563.1.p & scaffold_3659 & 1 & 1555 & 406 & 5,26 & 45011.1 & 36.59 & stabil \\
\hline EgHsp70-02 & Eucgr.E01024.1.p & 5 & 9739020 & 9743484 & 719 & 5,32 & 79530.1 & 32.23 & stabil \\
\hline
\end{tabular}




\section{Okaliptüs Hsp70 proteinlerinin akrabalık ilişkileri \\ EgHsp70 proteinlerinin akrabalık} ilişkilerini belirlemek amaciyla protein dizileri MEGA5 programında ClustalW dizi hizalama yöntemi kullanılarak hizalanmıştır (Thompson ve ark., 1997; Tamura ve ark., 2011). Daha sonra hizalanan bu diziler kullanılarak maksimum benzerlik metodu aracılığıyla 1000 tekrarlı 'bootstrap' analizleri ile filogenetik ağaç oluşturulmuştur. Elde edilen filogenetik ağaçta oluşan sinıfları belirtmek amaciyla bu ağaç ITOL (Interactive Tree Of Life) veri tabanında (Letunic ve Bork, 2016) düzenlenmiştir.

\section{Okaliptüs Hsp70 genleri için ontoloji analizleri}

Fonksiyonel eşleştirme yapan bir biyoinformatik platformu olan Blast2GO programina (http://www.blast2go.com) (Conesa ve Götz, 2008) EgHsp70 proteinleri aminoasit dizileri yüklenmiştir. $\mathrm{Bu}$ program aracılığıyla EgHsp70 proteinleri için tahmini moleküler fonksiyonlar, hücresel yerleşim ve biyolojik roller belirlenmiştir.

\section{Okaliptüs Hsp70 proteinlerinin tahmini üç boyutlu yapılarının belirlenmesi}

BLASTP taramas1, bütün EgHsp70 proteinleri için biyolojik moleküllerin üç boyutlu yapıları hakkında kaynak sağlayan Protein Data Bankasinda (PDB) benzer diziye sahip ve üç boyutlu yapısı bilinen en yakın proteini belirlemek amacıyla yapılmıştır. Elde edilen sonuçlar tahmini protein yapısının belirlenmesinde kullanışlı bir araç olan Pyre2 programinda

(Protein Homology/Analog/YRecognition Engine; http://www.sbg.bio.ic.ac.uk/phyre2)

homoloji modellemesi aracıllğıyla tahmini protein yapisının gösterilmesinde kullanılmıștır (Kelley ve Sternberg 2009).

\section{Bulgular ve Tartışma \\ Hsp70 gen ailesi üyelerinin okaliptüs genomunda tanımlanması}

Hspir veritabanından (Kumar ve ark., 2012) elde edilen ve Arabidopsis, salatalık, soya, arpa, yonca, tütün, çeltik, yosun, Hint yağ1 bitkisi, domates, sorgum, ekmeklik buğday, Maş fasulyesi, asma ve mısırı içeren
15 farklı bitkiye ait $\mathrm{Hsp} 70$ protein dizileri kullanılarak yapılan çoklu aramalar ve korunmuş bölge taramaları ile okaliptüs genomunda Hsp70 proteinini kodlayan 21 adet gen belirlenmiştir. Belirlenen bu genler, okaliptüs kromozomları üzerindeki yerleşimlerine göre 1'den (EgHsp70-01) 21'e (EgHsp70-21) kadar isimlendirilmişlerdir. EgHsp70-20 ve EgHsp70-21 proteinleri için ise kromozomal yerleşim belirlenememiştir. Daha önce $H s p 70$ genlerinin analiz edildiği soya, kavak, çeltik, pamuk ve Arabidopsis'de yapılan çalışmalarda ise sırasıyla $61,34,32$, 30 ve 18 adet $H s p 70$ geni belirlenmiștir (Lin ve ark., 2001; Sung ve ark., 2001; Jung ve ark., 2013; Sarkar ve ark., 2013; Zhang ve ark., 2014; Zhang L. ve ark., 2015; Yer ve ark., 2016). Şimdiye kadar çalışılan bitkiler içerisinde Arabidopsis'den sonra en az Hsp 70 geni okaliptüste tanımlanmıştır.

$\mathrm{Bu}$ grup proteinlerin aminoasit (aa) içeriklerine bakıldığında EgHsp70-21, en kısa protein dizisine sahip iken (406 aa), EgHsp7001 ise en fazla aminoasit içeriğine sahipti (939 aa). Moleküler ağırlıkları ise $103158.5 \mathrm{kDa}$ ile $45011.1 \mathrm{kDa}$ arasında değişmekteydi. İzoelektrik nokta (pI) değerlerine bakıldığında ise EgHsp70 proteinlerinin tamamının asidik karakterde $(\mathrm{pI}<7)$ olduğu gözlenmiştir. Kararsızlık endeksleri incelendiğinde $16 \mathrm{EgHsp} 70$ proteininin stabil olduğu söylenebilir (eşik değeri<40) (Tablo 1). Soya ve kavak bitkilerinde tanımlanan Hsp70 proteinlerinin büyük çoğunluğunun da asidik karakterde olduğu belirlenmiştir (Zhang L. ve ark., 2015; Yer ve ark., 2016). Buna göre bu özellik bu protein grubunun karakteristik özelliği olabilir.

Hsp70 gen ailesi üyelerinin okaliptüs kromozomlarında yerleşimleri ve gen organizasyonları

Belirlenen EgHsp70 genleri, 11 okaliptüs kromozomu üzerinde haritalanmış ve baz çifti cinsinden yerleşim yerleri de Tablo 1'de gösterilmiştir. Buna göre en çok EgHsp70 genini içeren ( 7 adet) 10 numaralı okaliptüs kromozomu olurken, bunu 3 adet EgHsp70 geni ile kromozom 6 takip etmiştir. Kromozom 5, 7, 8 ve 9 ikişer adet EgHsp70 geni bulundururken 3. kromozomda 1 adet EgHsp70 geni belirlenmiştir. Kromozom 1, 
2,4 ve 11'de ise EgHsp70 genine rastlanmamıştır (Şekil 1).
EgHsp70 ailesinin gen organizasyonları hakkında bilgi edinebilmek için ekzon ve intron yapılarına bakılmıştır (Şekil 2).

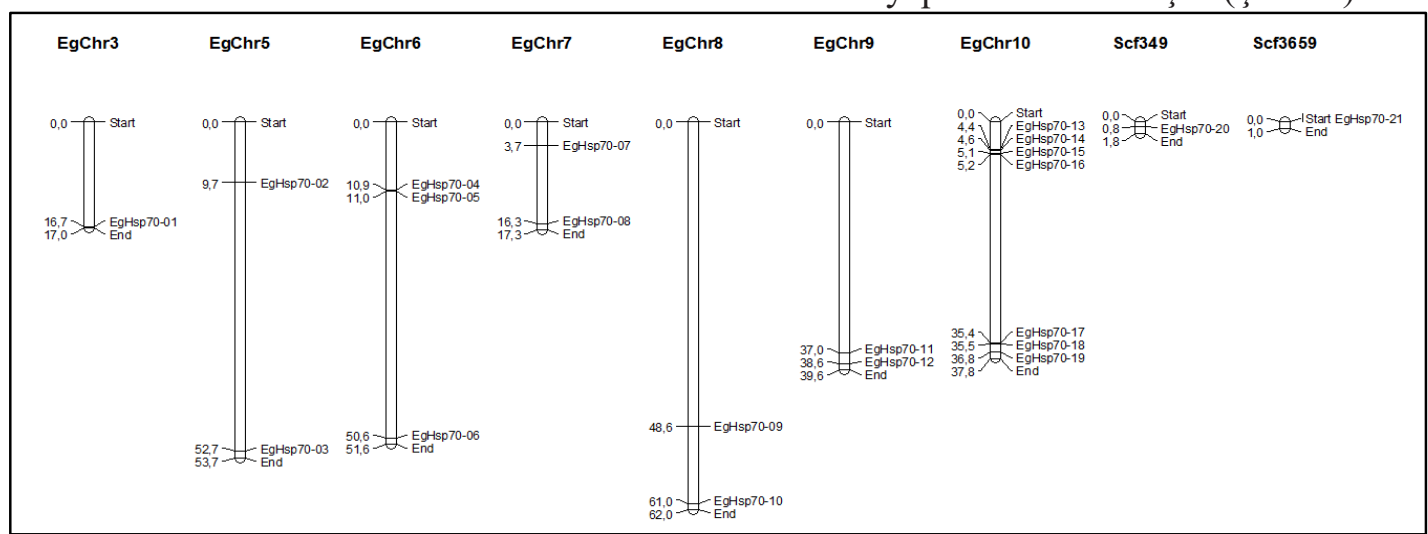

Şekil 1. EgHsp70 genlerinin 11 okaliptüs kromozomu üzerindeki dağılımı

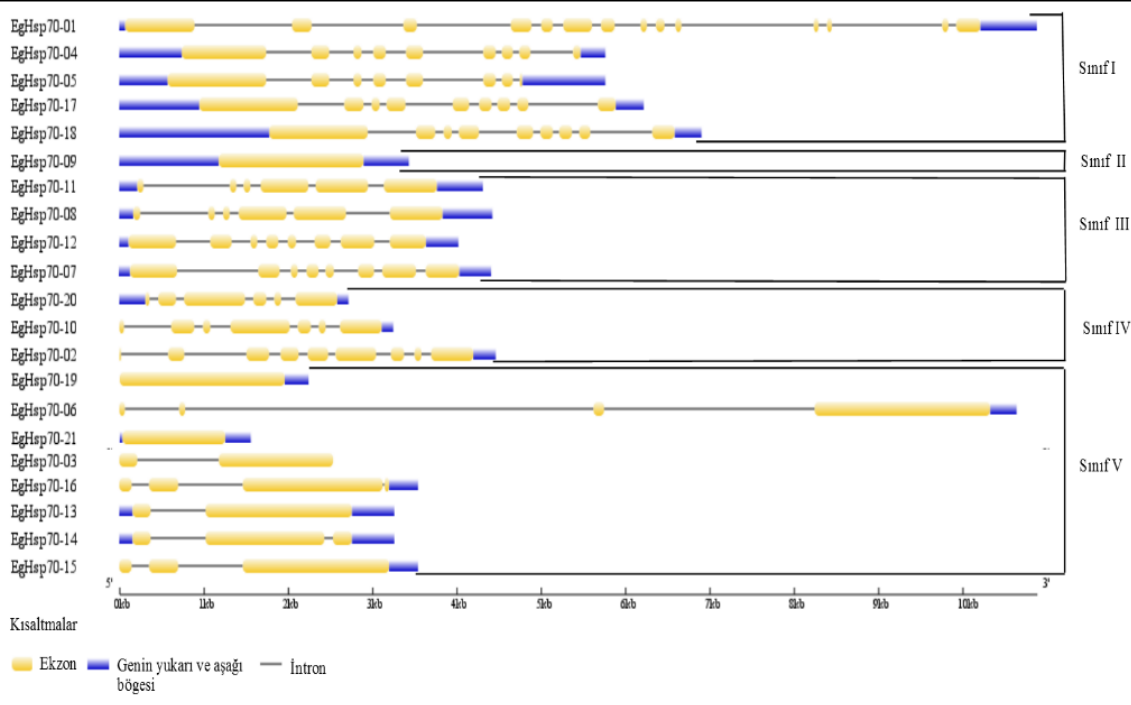

Şekil 2. Filogenetik ağaca göre sınıflandırılmış $E g H s p 70$ genlerinin ekzon-intron organizasyonu (Sarı çizgiler ekzon, gri çizgiler ise intronları göstermektedir)

$\mathrm{Bu}$ analizlere göre filogenetik ağaçta aynı grupta yer alan proteinlerin gen yapis1 genellikle benzer ekzon-intron organizasyonuna sahiptir. Örnek verilecek olursa Sinif V'de yer alan EgHsp 70 gen ailesi üyeleri genellikle iki veya üç intron ve ekzon içerirken, Sınıf I'de yer alan protein genlerinin ise genellikle 7-8 veya bazen daha fazla intron içerdiği ve diğer gruplara göre daha kısa ekzonlara sahip olduğu gözlenmiştir. Sınıf V'de yer alan EgHsp70-19 ve $E g H s p 70-21$ genlerinin ve Sinif II'de yer alan EgHsp70-09'un ise intron içermediği belirlenmiştir. Kavak ve soya $H s p 70$ genleri arasında da intron içermeyenler görülmüş ve okaliptüste olduğu gibi genellikle aynı grupta yer alan proteinlerin benzer ekzon-intron organizasyonuna sahip olduğu gözlenmiştir (Zhang L. ve ark., 2015; Yer ve ark., 2016).

\section{Belirlenen EgHsp70 proteinlerinin akrabalık ilișkileri \\ EgHsp70 proteinlerinin evrimsel} ilişkilerini belirlemek amacıyla filogenetik analizler yapılmıştır. Filogenetik ağaç, belirlenen 21 adet EgHsp70 proteini için maksimum benzerlik metodu aracılığıyla Jones-Taylor-Thornton (JTT) değişim modeli kullanılarak oluşturulmuştur (Şekil 3). 


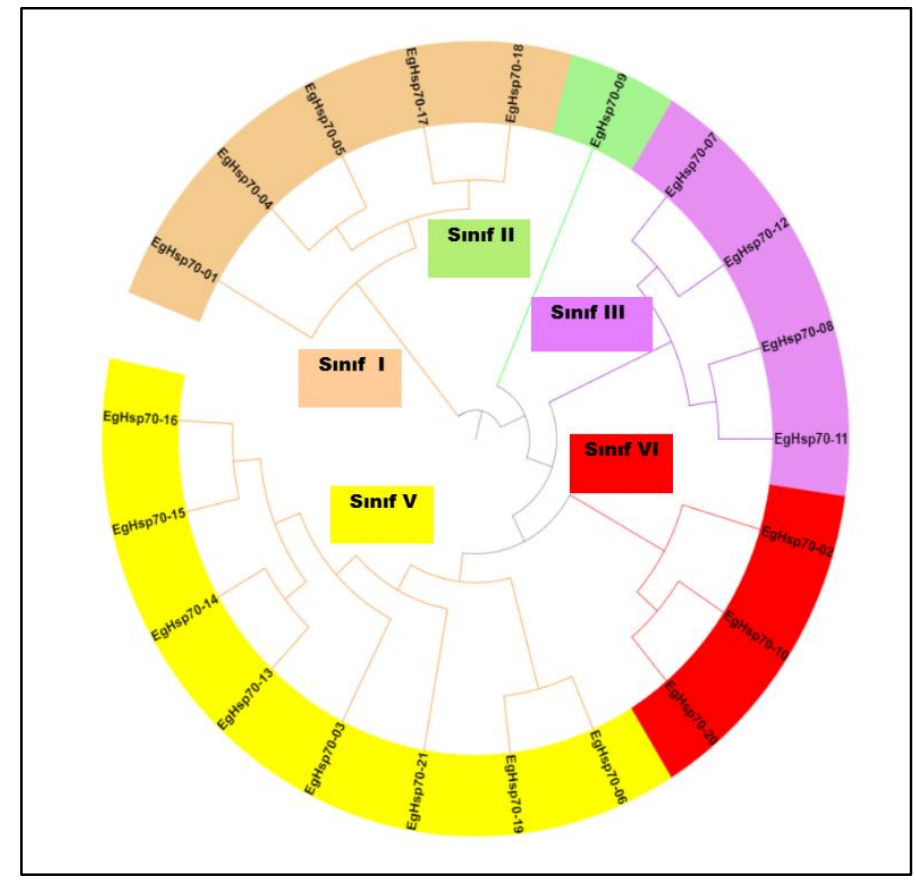

Şekil 3. EgHsp70 proteinlerinin filogenetik olarak sınıflandırılması (Sınıf I'den V'e kadar her sınıf ayrı bir renk ile gösterilmiştir)

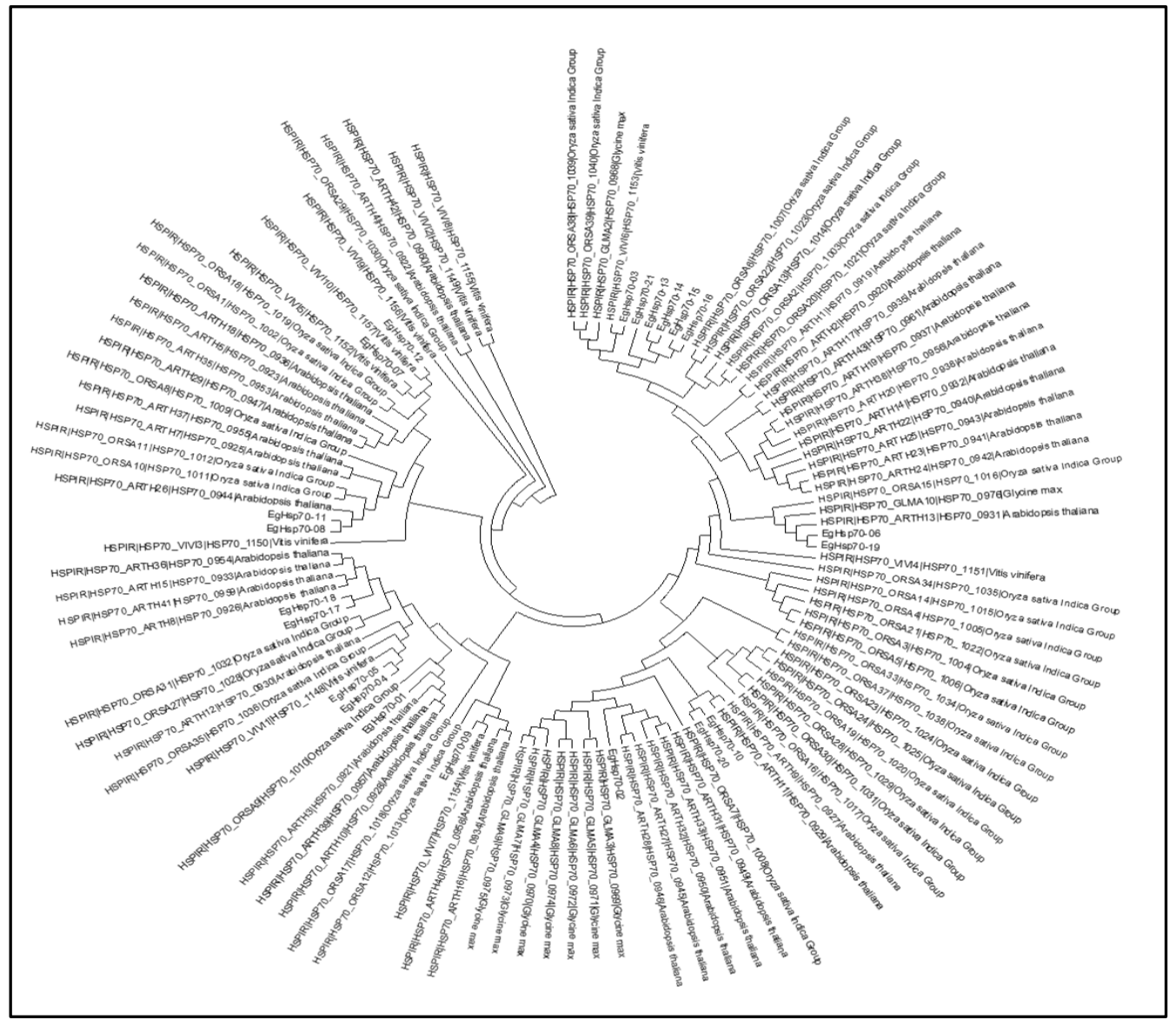

Şekil 4. Farklı bazı bitki türlerindeki Hsp70 proteinleri ile EgHsp70 proteinleri arasındaki filogenetik ilişkiler 
Elde edilen ağaca göre EgHsp70 proteinleri 5 ayrı gruba ayrılmış ve Sınıf I'den Sınıf V'e kadar isimlendirilmiştir. Sınıf V, sekiz protein ile en fazla EgHsp70 proteini bulunduran grup olurken bunu sirasıyla beş proteinle Sınıf I, dört proteinle Sinıf III, üç proteinle Sinıf IV ve bir proteinle Sinıf II takip etmiştir. Kavakta yapılan çalışmada ise Hsp70 proteinleri üç büyük sınıf oluşturmuş bunlardan III. Sınıf da kendi arasında üç gruba ayrılmıștır. Mitokondride yerleșim gösterdikleri belirlenen EgHsp70-08 ve EgHsp70-11 proteinlerinin aynı sinıfta (Sinıf III) yer aldığ 1 görülmüștür (Tablo 2). Buna göre siniflandirmada benzer bölgelerde yerleşim gösterenlerin birbirine yakın amino asit yapısına sahip olduğu ve bunun için aynı grupta yer aldığı söylenebilir. Ayrıca daha önce çeltikte yapılan çalışmada, aynı filogenetik sinifta yer alan Hsp70 proteinlerinin benzer ekzon-intron organizasyonuna sahip olduğu belirtilmiştir
(Jung ve ark., 2013). Bu da çalıșmamızın daha önce yapılan çalışmalarla uygunluk gösterdiğinin ve sinıflandırmanın yüksek güvenilirlikte olduğunun kanıtı olabilir.

Ayrica Hspir veritabanından (http://pdslab.biochem.iisc.ernet.in/hspir)

(Kumar ve ark., 2012) indirilen Arabidopsis, çeltik, soya ve asma gibi bitkilere ait Hsp70 protein dizileri ve elde edilen okaliptüs Hsp70 protein dizileri arasındaki akrabalık ilişkilerini analiz etmek amaciyla Mega 5 programı kullanılarak maksimum benzerlik metodu aracilığıyla filogenetik ağaç oluşturulmuștur (Şekil 4). Bu ağaca göre 4 ana sinıf oluşmuş, EgHsp70 proteinlerinin çoğunluğunun oluşan sinıflardan genellikle Arabidopsis (Arabidopsis thaliana) ve çeltik (Oryza sativa) Hsp70 protein dizilerini içeren gruplarda yer aldığı görülmüştür. $\mathrm{Bu}$ da okaliptüs Hsp70 proteinlerinin daha çok Arabidopsis ve çeltik bitkilerindekilere yakın olduğu fikrini vermektedir.

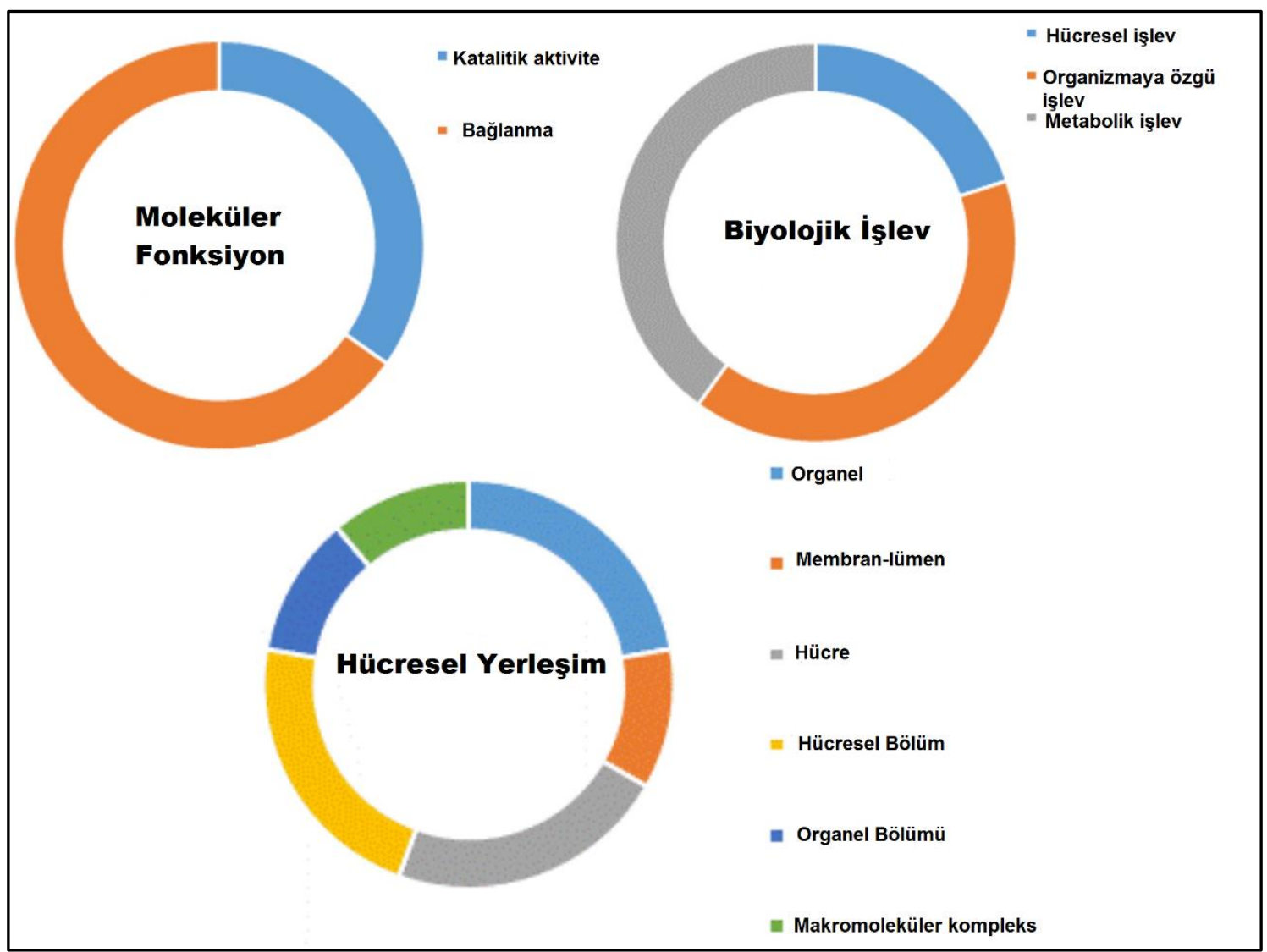

Şekil 5. EgHsp70 proteinlerinin gen ontolojisi analizleri (grafiklerin yanındaki her farklı renk, EgHsp70 proteinlerine ait farklı bir moleküler fonksiyon, biyolojik işlev ve hücresel yerleșimi ifade etmektedir) 
Tablo 2. Ayrıntılı gen ontoloji (GO) analizleri

\begin{tabular}{|c|c|c|c|c|c|c|c|c|}
\hline Gen adı & Tanımı & Uzunluğu & e-değeri & $\begin{array}{l}\text { Benzerlik } \\
\text { ortalaması }\end{array}$ & $\begin{array}{l}\text { GO Biyolojik } \\
\text { Fonksiyonu }\end{array}$ & GO Moleküler Fonksiyonu & $\begin{array}{l}\text { GO Hücresel } \\
\text { Yerleşimi }\end{array}$ & Gen adı \\
\hline EgHsp70-07 & $\begin{array}{l}\text { Stromal } 70 \mathrm{kDa} 1 \mathrm{s1} \\
\text { şoku-ilişkili } \\
\text { kloroplastik }\end{array}$ & 706 & $0.0 \mathrm{E} 0$ & $91.85 \%$ & $\begin{array}{l}\text { Oksidasyon redüksiyon } \\
\text { süreçleri; protein } \\
\text { katlanmasi }\end{array}$ & $\begin{array}{l}\text { ATP'ye bağlanma; 2-alkenal redüktaz } \\
\text { [NAD(P)] aktivitesi; katlanmamış } \\
\text { proteine bağlanma; }\end{array}$ & & EgHsp70-07 \\
\hline EgHsp70-08 & $\begin{array}{l}\text { Is1 şoku } 70 \mathrm{kDa} \\
\text { mitokondriyal }\end{array}$ & 684 & $0.0 \mathrm{E} 0$ & $95.35 \%$ & Protein katlanması & $\begin{array}{l}\text { ATP'ye bağlanma; katlanmamış } \\
\text { proteine bağlanma; }\end{array}$ & Mitokondri & EgHsp70-08 \\
\hline EgHsp70-09 & Is1 şoku $70 \mathrm{kDa} 8$ & 572 & $0.0 \mathrm{E} 0$ & $91.65 \%$ & $\begin{array}{l}\text { Oksidasyon redüksiyon } \\
\text { süreçleri }\end{array}$ & $\begin{array}{l}\text { ATP'ye bağlanma; 2-alkenal redüktaz } \\
\text { [NAD(P)] aktivitesi; katlanmamış } \\
\text { proteine bağlanma; }\end{array}$ & & EgHsp70-09 \\
\hline EgHsp70-10 & $\begin{array}{l}\text { Luminal-bağlanma } \\
\text { 5-benzeri }\end{array}$ & 618 & $0.0 \mathrm{E} 0$ & $89.6 \%$ & ATP bağlanması & & $\begin{array}{l}\begin{array}{l}\text { Mediator } \\
\text { kompleksi }\end{array} \\
\end{array}$ & EgHsp70-10 \\
\hline EgHsp70-11 & $\begin{array}{l}\text { Is1 şoku } 70 \mathrm{kDa} \\
\text { mitokondriyal }\end{array}$ & 682 & $0.0 \mathrm{E} 0$ & $94.45 \%$ & $\begin{array}{l}\text { Oksidasyon redüksiyon } \\
\text { süreçleri; protein }\end{array}$ & $\begin{array}{l}\text { ATP'ye bağlanma; 2-alkenal redüktaz } \\
\text { [NAD(P)] aktivitesi; katlanmamış } \\
\text { proteine bağlanma; }\end{array}$ & Mitokondri & EgHsp70-11 \\
\hline EgHsp70-12 & $\begin{array}{l}\text { Stromal } 70 \mathrm{kDa} 1 \mathrm{s1} \\
\text { şoku-iliskili } \\
\text { kloroplastik }\end{array}$ & 718 & $0.0 \mathrm{E} 0$ & $91.45 \%$ & $\begin{array}{l}\text { Oksidasyon redüksiyon } \\
\text { süreçleri; protein } \\
\text { katlanmasi }\end{array}$ & $\begin{array}{l}\text { ATP'ye bağlanma; 2-alkenal redüktaz } \\
\text { [NAD(P)] aktivitesi; katlanmamış } \\
\text { proteine bağlanma; }\end{array}$ & & EgHsp70-12 \\
\hline EgHsp70-13 & $\begin{array}{l}\text { Is1 şoku cinsi } 70 \\
\text { kDa } 2\end{array}$ & 649 & $0.0 \mathrm{E} 0$ & $98.3 \%$ & $\begin{array}{l}\text { Oksidasyon redüksiyon } \\
\text { süreçleri }\end{array}$ & $\begin{array}{l}\text { ATP'ye bağlanma; 2-alkenal redüktaz } \\
\text { [NAD(P)] aktivitesi; katlanmamış } \\
\text { proteine bağlanma; }\end{array}$ & & EgHsp70-13 \\
\hline EgHsp70-14 & $\begin{array}{l}\text { Isı şoku cinsi } 70 \\
\text { kDa 2-benzeri }\end{array}$ & 615 & $0.0 \mathrm{E} 0$ & $94 \%$ & & ATP'ye bağlanma & & EgHsp70-14 \\
\hline EgHsp70-15 & $\begin{array}{l}\text { Isı şoku cinsi } 70 \\
\text { kDa 2-benzeri }\end{array}$ & 742 & $0.0 \mathrm{E} 0$ & $98.05 \%$ & & ATP'ye bağlanma & & EgHsp70-15 \\
\hline EgHsp70-16 & $\begin{array}{l}\text { Is1 şoku cinsi } 70 \\
\text { kDa 2-benzeri }\end{array}$ & 735 & $0.0 \mathrm{E} 0$ & $98.25 \%$ & & ATP'ye bağlanma & & EgHsp70-16 \\
\hline EgHsp70-17 & $\begin{array}{l}\text { Is1 şoku cinsi } 70 \\
\text { kDa } 15 \text {-benzeri }\end{array}$ & 851 & $0.0 \mathrm{E} 0$ & $89.15 \%$ & $\begin{array}{l}\text { Oksidasyon redüksiyon } \\
\text { süreçleri }\end{array}$ & $\begin{array}{l}\text { ATP'ye bağlanma; 2-alkenal redüktaz } \\
\text { [NAD(P)] aktivitesi; katlanmamış } \\
\text { proteine bağlanma; }\end{array}$ & & EgHsp70-17 \\
\hline EgHsp70-18 & $\begin{array}{l}\text { Is1 şoku cinsi } 70 \\
\text { kDa } 15 \text {-benzeri }\end{array}$ & 874 & $0.0 \mathrm{E} 0$ & $91.65 \%$ & $\begin{array}{l}\text { Oksidasyon redüksiyon } \\
\text { süreçleri }\end{array}$ & $\begin{array}{l}\text { ATP'ye bağlanma; 2-alkenal redüktaz } \\
{[N A D(P)] \text { aktivitesi; katlanmamış }} \\
\text { proteine bağlanma; }\end{array}$ & & EgHsp70-18 \\
\hline EgHsp70-19 & Is1 şoku $70 \mathrm{kDa}$ & 652 & $0.0 \mathrm{E} 0$ & $97.15 \%$ & $\begin{array}{l}\text { Oksidasyon redüksiyon } \\
\text { süreçleri }\end{array}$ & $\begin{array}{l}\text { ATP'ye bağlanma; 2-alkenal redüktaz } \\
\text { [NAD(P)] aktivitesi; katlanmamış } \\
\text { proteine bağlanma; }\end{array}$ & & EgHsp70-19 \\
\hline EgHsp70-20 & $\begin{array}{l}\text { Luminal-bağlanma } \\
\text { 5-benzeri }\end{array}$ & 572 & $0.0 \mathrm{E} 0$ & $96.4 \%$ & ATP bağlanması & & $\begin{array}{l}\text { Mediator } \\
\text { kompleksi }\end{array}$ & EgHsp70-20 \\
\hline EgHsp70-21 & $\begin{array}{l}\text { Is1 şoku cinsi } 70 \\
\mathrm{kDa} 2\end{array}$ & 406 & $0.0 \mathrm{E} 0$ & $97.45 \%$ & ATP bağlanması & & & EgHsp70-21 \\
\hline
\end{tabular}




\section{EgHsp70 gen ontolojileri}

EgHsp70 genleri için moleküler fonksiyon, hücresel yerleşim ve biyolojik işlev analizleri Blast2GO programı kullanılarak yapılmıştır (Şekil 5). Buna göre moleküler fonksiyon olarak bu gen ailesi üyelerinin bağlanma ve katalitik aktivite gösterdikleri belirlenmiştir. $\mathrm{Bu}$ proteinlerin önemli görevlerinden olan protein katlanmas1 sırasındaki rolleri göz önüne alındığında ağırlıklı belirlenen bu fonksiyon uyumlu gözükmektedir. Bu grup proteinlerin hücresel yerleșimi için belirlenen 6 farklı bölgeden en yaygın olarak yerleștikleri kısımların hücre içi, organel veya hücre bölümü olduğu gözlenmiştir. Daha önce yapılan çalışmalardan soyada; 27 adet sitozol, 17 adet organel, 6 adet nükleus, 3 adet plazma zarı ve 1 adet de hücre iskeleti yerleşimli Hsp70 proteinine rastlanmıştır (Zhang L. ve ark., 2015). Arabidopsis Hsp70 proteinleri arasında 5 adet sitozolik yerleșimli belirlenirken (Lin ve ark., 2001), çeltikte 11 adet nükleo/sitozolik yerleşimli Hsp70 proteini gözlenmiştir (Jung ve ark., 2013; Sarkar ve ark., 2013). Ayrıca kavakta yapılan çalışmada ise 17 tanesi hücre içi ve sitoplazma, hücre zarı, hücre duvarı, sitozol ve nükleus gibi hücre kısımlarında yerleşim gösterirken diğerlerinin ise organel yerleşimli olduğu saptanmıştır (Yer ve ark., 2016). Buna ek olarak daha önce Arabidopsis'de yapilan başka bir çalışmada Hsp70 grup proteinlerinin sitozol, endoplazmik retikulum (ER), plastidler ve mitokondri olmak üzere hücre içerisindeki yerleşimlerine göre dört farklı alt gruba ayrilabileceği belirtilmiştir (Sung ve ark., 2001). Bunlar göz önüne alındığında elde ettiğimiz sonuçlar daha önceki çalıșmalarla uyumludur ve bu proteinlerin yerleșimlerinin genellikle hücre içi ve kısımları olduğu görülmektedir. Farklı hücresel bölümlerde yerleşmeleri ise onların pek çok farlı hücresel görevleri ile ilişkilendirilebilir. Tahmini biyolojik işlevleri analiz edildiğinde ise gözlenen 3 farklı kategoriden baskın olanların organizmaya özgü ve metabolik işlevlerdeki rolleri olduğu belirlenmiştir.
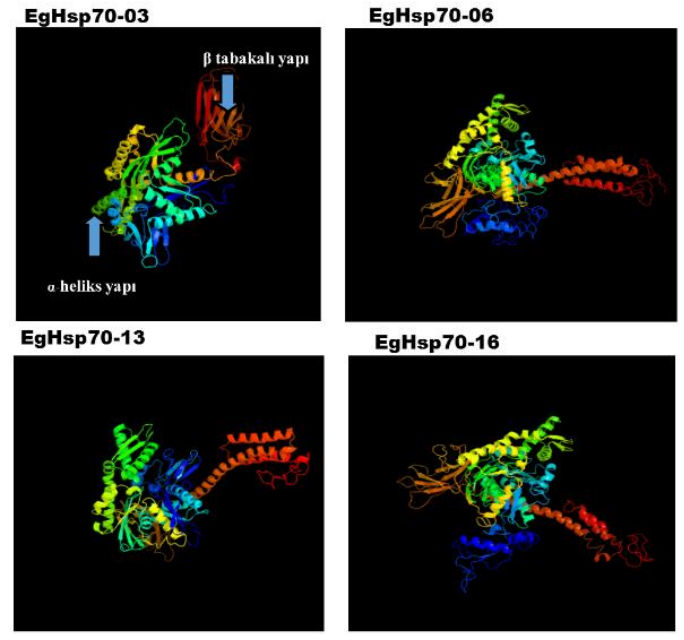

EgHsp70-19

EgHsp70-21
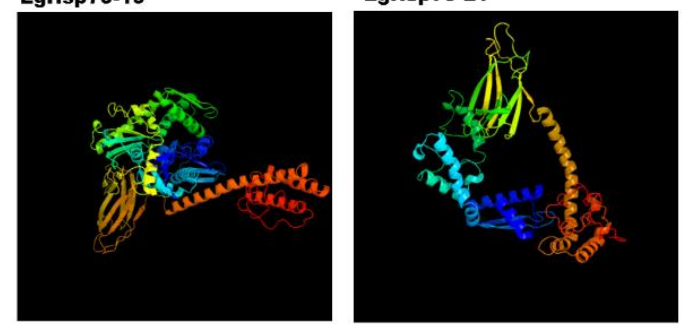

Şekil 6. EgHsp70 proteinlerine ait tahmini üç boyutlu yapıların gösterimi

EgHsp70 proteinlerinin tahmini üç boyutlu yapıları

Protein Veri Bankası (PDB) içerisinde yapilan BLASTP araması sonucu belirlenen oranlar için Phyre2 veri tabanında yoğun mod seçilerek Hidden Markov Model (HMM) taraması yapılmıs ve bu proteinlere ait tahmini üç boyutlu yapılar belirlenmiştir. Modellenme yüzdesi \% 100 güven düzeyinde $\% 78$ ile $\%$ 83 arasında değişen oranlarda veri tabanındaki tanımlanmış proteinlerle yükssek benzerlik gösteren 6 adet EgHsp70 (EgHsp70-03-06-13-16-19-21) proteini Hsp70 protein ailesinin tahmini üç boyutlu yapısını göstermek üzere belirlenmiştir (Şekil 6) (EgHsp70-03 için PDB ismi:c3c7nB; EgHsp70-06 için PDB ismi:c3c7nB; EgHsp70-13 için PDB ismi:c1hpmA; EgHsp70-16 için PDB ismi:c3c7Nb; EgHsp70-19 PDB ismi:c3c7nB ve EgHsp70$21 \mathrm{PDB}$ ismi:c3c7Nb). Tahmini bu modellere göre yapıda sıklıkla $\alpha$-heliks zincirlerinin baskın olduğu belirlenirken az sayıda da olsa $\beta$ tabakalı yapıların da bulunduğu gözlenmiştir. Yapılan çalışmalarda Hsp70 proteinlerinin substrat bağlanma bölgesinin (SBD) $\mathrm{C}$ terminal alt bölgesinin $\alpha$-heliks 
zincirlerince zengin olduğu ve substrat bağlanmasında kapak görevi gördüğü belirlenmiştir (Lund 2001). Hsp70 proteini ADP bağlı olduğunda bu kapak kapanmakta ve peptidlerin SBD bölgesine sıkıca bağlanmasını sağlamaktadır. Kapak yapısı, şaperonun substrata ilgisini de düzenlemektedir. Substrat bağlanma bölgesi ise dört ipliğin her birinde iki antiparalel $\beta$ tabakası içeren $\beta$ sandviç yapısındadır. Peptidin bağlandığı bölge bu iki $\beta$ tabakasının arasinda bulunmakta ve helikal kapak ile kapatılan derin bir cep içermektedir (Mayer ve ark., 2001). Kavakta Hsp70 proteinlerinin de genellikle $\alpha$-heliks yapıya sahip olduğu, nadiren $\beta$ tabakalı yapının görüldüğü belirlenmiştir (Yer ve ark., 2016). Bu sonuçlara göre bu grup proteinlerin genellikle $\alpha$-heliks yapılardan oluştuğu söylenebilir. Ayrıca bu yapı, çalışmamız sonuçlarıyla uyumlu olup moleküler fonksiyonları için gerekli bir yapı biçimi olarak gözükmektedir.

\section{Sonuç}

Çalıșmamız sonucunda okaliptüs genomunda bulunan Hsp70 protein ailesine ait genler tanımlanmıs ve kromozomal yerleşimleri, gen yapıları, akrabalık ilişkileri, tahmini biyolojik fonksiyonları, hücresel yerleșimleri ve tahmini üç boyutlu yapıları gibi bazı karakteristik özellikleri belirlenmiştir. Sonuç olarak çalışmamız, $\mathrm{EgHsp} 70$ genlerinin fonksiyonlarının çalışı1ması için sonraki çalışmalara 1şık tutucu niteliktedir ve farkl1 türlerde $H s p 70$ genlerinin evriminin anlaşılmasına önemli katkılar sağlayabilir.

\section{Kaynaklar}

Alvim F.C., Carolino S.M., Cascardo J.C., Nunes C.C., Martinez C.A., Otoni W.C., Fontes E.P. 2001. Enhanced accumulation of $\mathrm{BiP}$ in transgenic plants confers tolerance to water stress. Plant Physiol, 126,1042-1054.

Bartholomé J., Mandrou E., Mabiala A., Jenkins J., Nabihoudine I., Klopp C., Schmutz J., Plomion C., Gion J.M. 2015. High-resolution genetic maps of Eucalyptus improve Eucalyptus grandis genome assembly. The New phytologist, 206 (4), 1283-96.

Bukau B., Horwich A.L. 1998. The Hsp70 and Hsp60 chaperone machines. Cell, 92, 351-366.

Byrne M. 2008. Phylogeny, diversity and evolution of eucalypts. in Plant Genome:
Biodiversity and Evolution, Part E: PhanerogamsAngiosperm Vol. 1 (eds Sharma, A. K. \& Sharma, A.) 303-346 (Science Publishers).

Cho E.K., Choi Y.J. 2009. A nuclear-localized HSP70 confers thermo protective activity and drought-stress tolerance on plants. Biotechnol Lett, 31, 597-606.

Conesa A., Götz S. 2008. Blast2GO: a comprehensive suite for functional analysis in plant genomics. Int J Plant Genomics, 619832.

Dragovic Z., Broadley S.A., Shomura Y., Bracher A., Hartl F.U. 2006. Molecular chaperones of the Hsp110 family act as nucleotide exchange factors of Hsp70s. EMBO J, 25, 25192528

Duck N.B., Folk W.R. 1994. Hsp70 heat shock protein cognate is expressed and stored in developing tomato pollen. Plant Mol Biol, 26, 1031-103.

Hartl F.U., Bracher A., Hayer-Hartl M. 2011. Molecular chaperones in protein folding and proteostasis. Nature, 475, 324-332.

He Z., Xie R., Wang Y., Zou H., Zhu J., and $\mathrm{Yu}, \mathrm{G} .2008$. Cloning and characterization of a heat shock protein 70 gene, MsHSP70-1, in Medicago sativa. Acta Biochim Biophys Sin, 40,209-216.

Hu B., Jin J., Guo A.Y., Zhang H., Luo J. and Gao G. 2015. GSDS 2.0: an upgraded gene feature visualization server. Bioinformatics, 31(8), 12961297

Gasteiger E., Gattiker A., Hoogland C., Ivanyi I., Appel R.D., and Bairoch A. 2003. ExPASy: theproteomicsserverforin-depthprotein knowledge and analysis. Nucl Acids Res, 31,3784-3788.

Goodstein D.M., Shu S., Howson R., Neupane R., Hayes R.D., Fazo J., Mitros T., Dirks W., Hellsten U., Putnam N., Rokshar D.S. 2012. Phytozome: a 14 comparative platform for green plant genomics. Nucleic Acids Res, 40, D1178D1186.

Gülbaba A.G. 1990. Okaliptus'ta Döl Denemeleri, Doğu Akdeniz Ormancıllk Araştırma Enstitüsü Dergisi, Tarsus.

Iglesias I., Wiltermann, D. 2009. in Eucalyptologics Information Resources on Eucalypt Cultivation Worldwide http://www.gitforestry.com (GIT Forestry Consulting, retrieved, 29 March 2009).

Jung K.H., Gho H.J., Nguyen M.X., Kim S.R., An G. 2013. Genome-wide expression analysis of HSP70 family genes in rice and identification of a cytosolic HSP70 gene highly induced under heat stress. Funct Integr Genomics, 13(3), 391-402.

Jungkunz I., Link K., Vogel F., Voll L.M., Sonnewald S., and Sonnewald U. 2011. AtHSP7015-deficientArabidopsis plants are characterized by reduced growth, a constitutive cytosolic protein 
response and enhanced resistance to TuMV. Plant J, 66, 983-995.

Kelley L.A., Sternberg M.J.E. 2009. Protein structure prediction on the web: a case study using the Phyre server. Nat Protoc, 4, 363-371.

Krishna P., Sacco M., Cherutti J.F. and Hill S. 1995. Cold-induced accumulation of hsp90 transcripts in Brassica napus. Plant Physiol, 107,915-923.

Kumar R., Nagarajan N.S., Arunraj S.P., Devanjan S., Rajan V.B.V., Esthaki V.K., and D'Silva P. 2012. HSPIR: a manually annotated heat shock protein information resource. Bioinformatics, 28 (21), 2853-2855.

Letunic I., Doerks T., Bork P. 2012. SMART 7: recent updates to the protein domain annotation resource. Nucleic Acids Res 40(D1), D302-D305.

Letunic I., Bork P. 2016. Interactive tree of life (iTOL) v3: an online tool for the display and annotation of phylogenetic and other trees. Nucleic Acids Res, doi: 10.1093/nar/gkw290.

Lin B.L., Wang J.S., Liu H.C., Chen R.W., Meyer Y., Barakat A, Delseny M. 2001. Genomic analysis of the Hsp70 superfamily in Arabidopsis thaliana. Cell Stress Chaperones 6(3), 201-208.

Lopez-Matas M.A., Nuñez P., Soto A., Allona I., Casado R., Collada C., et al. 2004. Protein cryoprotective activity of a cytosolic small heat shock protein that accumulates constitutively in chestnut stems and is up- regulated by low and high temperatures. Plant Physiol, 134,1708-1717.

Lund P.A. 2001. Molecular chaperones in the cell. (Vol. 37) Oxford University Press, Oxford.

Mayer, M.P., Brehmer, D., Gassler, C.S. and Bukau, B. 2001. Hsp70 chaperone machines. Adv Protein Chem, 59, 1-44.

Mayer M.P. and Bukau, B. 2005. Hsp70 chaperones: cellular functions and molecular mechanism. Cell Mol Life Sci, 62, 670-684.

Maruyama D., Endo T., Nishikawa S. 2010. $\mathrm{BiP}-$ mediated polar nuclei fusion is essential for the regulation of endosperm nuclei proliferation in Arabidopsis thaliana. Proc Natl Acad Sci USA, 107, 1684- 1689.

Myburg A.A., Grattapaglia D., Tuskan G.A., Hellsten U., Hayes R.D., Grimwood J., ... \& Goodstein D.M. 2014. The genome of Eucalyptus grandis. Nature, 510 (7505), 356-362.

Qi Y., Wang H., Zou Y., Liu C., Liu Y., Wang Y., Zhang W. 2011. Overexpression of mitochondrial heat shock protein 70 suppresses programmed cell death in rice. FEBS Lett, 585, 231-239.

Ritossa F. 1996. Discovery of the heat shock response. Cell Stress Chaperones 1, 97-98.

Sabehat A., Lurie S., and Weiss D. 1998. Expression of small heat-shock protein sat low temperatures. A possible role in protecting against chilling injuries. Plant Physiol, 117,651-658.

Sarkar N.K., Kundnani P., Grover A. 2013. Functional analysis of Hsp70 superfamily proteins of rice (Oryza sativa). Cell Stress Chaperones 18(4), 427-437.

Sung D.Y., Vierling E., Guy C.L. 2001. Comprehensive expression profile analysis of the Arabidopsis Hsp70 gene family. Plant Physiol, 126(2), 789-800.

Su P.H. Li H.M. 2008. Arabidopsis stromal 70$\mathrm{kD}$ heat shock proteins are essential for plant development and important for thermotolerance of germinating seeds. Plant Physiol, 146, 1231-1241.

Swindell W.R., Huebner M., and Weber A.P. 2007. Transcriptional profiling of Arabidopsis heat shock proteins and transcription factors reveals extensive overlap between heat and nonheat stress response pathways. BMC Genomics, 8 , 125.doi:10.1186/1471-2164-8-125.

Tamura K., Peterson D., Peterson N., Stecher G., Nei M., \& Kumar S. 2011. MEGA5: molecular evolutionary genetics analysis using maximum likelihood, evolutionary distance, and maximum parsimony methods. Molecular biology and evolution, 28(10), 2731-2739.

Thompson J.D., Gibson T.J., Plewniak F. et al. 1997. The CLUSTAL_X windows interface: flexible strategies for multiple sequence alignment aided by quality analysis tools. Nucleic Acids Res, 25, 4876-4882

Voorrips R.E. 2002. MapChart: software for the graphical presentation of linkage maps and QTLs. J Hered 93, 77-78.

Wakasa Y., Yasuda H., Oono Y., Kawakatsu T., Hirose S., Takahashi H., Hayashi S., Yang L., Takaiwa F. 2011. Expression of ER qualitycontrolrelated genes in response to changes in BiP1 levels in developing rice endosperm. Plant J, 65, 675689.

Wang W., Vinocur B., Shoseyov O., and Altman A. 2004. Role of plant heat-shock proteins and molecular chaperones in the abiotic stress response. Trends Plant Sci, 9, 244-252.

Yer E.N., Baloglu M.C., Ziplar U.T., Ayan S., Unver T. 2016. Drought-Responsive Hsp70 Gene Analysis in Populus at Genome-Wide Level. Plant Mol Biol Rep, 34, 483-500.

Zhang L., Zhao H.K., Dong Q.L., Zhang Y.Y., Wang Y.M., Li H.Y., ... \& Dong Y.S. 2015. Genome-wide analysis and expression profiling under heat and drought treatments of HSP70 gene family in soybean (Glycine max L.).Frontiers in plant science, 6 .

Zhang Y., Wang M., Chen J., Rong J., Ding M. 2014. Genome-wide analysis of HSP70 superfamily in Gossypium raimondii and the 
expression of orthologs in Gossypium hirsutum. Yi Chuan, 36(9), 921-33. (Article in Chinese)

Zhang J., Liu B., Li J., Zhang L., Wang Y., Zheng H., Lu M., Chen J. 2015. Hsf and Hsp gene families in Populus: genome-wide identification, organization and correlated expression during development and in stress responses. BMC Genomics, 16, 181. doi:10.1186/s12864-0151398-3.

Zou J., Liu C., Liu A., Zou D., and Chen X. 2012. Overexpression of OsHsp17.0 and OsHsp23.7 enhances drought and salt tolerance in rice. J Plant Physiol. 169, 628-635. 